\title{
Recommendations for High Vitamin D Supplementation to help Fight the COVID- I 9 Pandemic and its Inclusion in National COVID- I 9 Management Guidelines
}

Jugal Kishore', David S Grimes ${ }^{2}$, David C Anderson 3 , Omesh Kumar Bharti ${ }^{4}$, Blessy Joseph ${ }^{5}$, Glory Ghai ${ }^{6}$, Monika Sahoo ${ }^{7}$

${ }^{1}$ Director Professor \& Head, ${ }^{5}$ Senior Resident, ${ }^{6}$ Resident, Department of Community Medicine, VMMC \& SJH, New Delhi, India. ${ }^{2}$ Retired Consultant Physician, East Lancashire.

${ }^{3}$ Retired Consultant Physician and Clinical Endocrinologist and former Professor of Medicine and Endocrinology, University of Manchester, Manchester, UK, and The Chinese University of Hong Kong.

${ }^{4}$ State Epidemiologist from Shimla, Himachal Pradesh, India.

${ }^{7}$ Senior Resident, Department of Obstetrics \&Gynaecology, VMMC \& SJH, New Delhi, India.

DOI: https://doi.org/10.24321/2349.2880.202104

\section{I $\quad \mathbf{N} \quad \mathbf{F} \quad \mathbf{O}$}

\section{Corresponding Author:}

Jugal Kishore, Department of Community Medicine, VMMC \& SJH, New Delhi, India.

E-mail Id:

drjugalkishore@gmail.com

Orcid Id:

https://orcid.org/0000-0001-6246-5880

How to cite this article:

Kishore J, Grimes DS, Anderson DC, Bharti OK, Joseph B, Ghai G, Sahoo M. Recommendations for High Vitamin D Supplementation to help Fight the COVID-19 Pandemic and its Inclusion in National COVID-19 Management Guidelines. Ind J Youth Adol Health. 2021;8(1):13-17.

Date of Submission: 2021-02-22

Date of Acceptance: 2021-03-15 $\begin{array}{lllllllllll}\text { B } & \text { A } & \text { C } & \text { K } & G & \text { R } & \text { O } & \text { U } & \text { N } & \text { D }\end{array}$ 
acute infections like COVID-19, and levels up to $100 \mathrm{ng} /$ $\mathrm{ml}$ are perfectly safe.

\section{Problem Statement}

India is grappling with the massive second wave of COVID-19 with the total positive cases nearing 2.9 crores. The death rate has been $1.22 \%$ with more than $70 \%$ of the reported deaths in individuals with associated comorbidities. ${ }^{5}$ India began the administration of COVID-19 vaccines on 16 January 2021 with a promise of conducting a large vaccination programme. However, it will take time to produce and procure vaccines particularly for the younger population (who in any case are at a much lower risk of the disease). ${ }^{6}$ In any case, the vaccines themselves do not address defective intrinsic immunity caused by vitam in $D$ deficiency. In view of the threat of future waves of COVID-19 or similar infections, simple additional alternatives are required.

This leaves two major factors upon which the Government and population need to focus to prevent any future devastating surge of COVID-19 cases and deaths viz., measures of personal protection and immune enhancement. ${ }^{7}$ For immune enhancement, vitamin $D$ presents a simple, safe, and inexpensive defence, but vitamin $D$ deficiency is quite rampant all over the country, increasing susceptibility to severe COVID-19 infection and consequent mortality. Reasons for this include cloud cover, atmospheric pollution, dark skin colour, sun avoidance, occlusive clothing and use of sunscreens. Numerous studies, both community- and hospital-based, throughout India, have reported vitamin D deficiency ranging from $40-99 \%$ with most citing a prevalence of $80-90 \%$ irrespective of age, sex, and geography. ${ }^{8}$ It is also important to maintain a diet adequate in vitamin $A$ (700 to $900 \mathrm{mcg}$ for an adult), as this acts with vitamin $D$.

\section{Role of Vitamin D Deficiency in COVID- 19}

A meta-analysis done in Europe indicated that countries with a high prevalence of vitamin D deficiency had much higher mortality than those in the equatorial region or where people had adequate levels of serum vitamin D. ${ }^{9}$ Kaufman et al. in the US, in a retrospective observational study, matched the results of SARS-CoV-2 testing with $25(\mathrm{OH}) \mathrm{D}$ results and showed an association between lower SARS-CoV-2 positivity rates and higher circulating $25(\mathrm{OH})$ $D$ levels, which remained significant in a multivariable logistic model adjusting for all included demographic factors (adjusted odds ratio [OR], 0.984 per ng/mL increment; $\mathrm{P}<$ 0.001)..$^{10}$ Another observational study in India reported an inverse correlation between serum vitamin $\mathrm{D}$ level and SARS-CoV- 2 infection rate. ${ }^{11}$

A controlled trial conducted in a COVID-19 ward in Spain showed a reduced mortality risk with an OR $0.21[95 \% \mathrm{Cl}$
$0.10 ; 0.43$ ] when calcifediol, $25(\mathrm{OH}) \mathrm{D}$, the activated form of vitamin D was given on admission. ${ }^{12}$ Jayawardena et al. reported positive correlations for the prevalence of vitamin $D$ deficiency with COVID-19 infections $(r=0.55 ; p=0.01$; $R 2=0.31)$ and mortalities $(r=0.50 ; p=0.01 ; R 2=0.25)$ in Asian countries. ${ }^{13} \mathrm{~A}$ randomised control trial in India likewise concluded that individuals with adequate vitamin D levels turned SARS-CoV-2 RNA negative far earlier than the individuals who had vitamin D deficiency. ${ }^{14}$ Rather in a recent study in India, it has been seen that high doses of vitamin D are required in COVID-19 patients in India for better chances of survival. ${ }^{14,21}$

From our personal experiences and observations in various categories of COVID patients in New Delhi, we have found quite promising results with calcifediol in ICU patients and vitamin D injections $(100,000$ units IM or orally) in those less sick. We have data of 95 participants which include 42 females and 53 males. Out of them, 20 were severe cases of COVID-19 whom we have given calcifediol capsule $50000 \mathrm{IU}$ stat and to others 3 lakh IU single dose (Figure 1). All patients recovered without any adverse outcome.
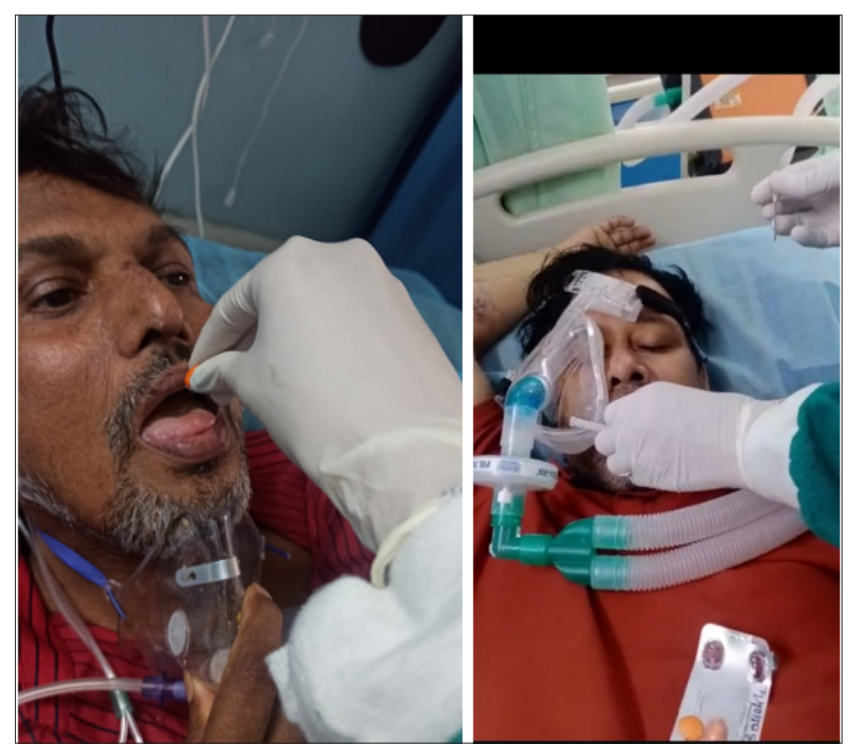

Figure I.Patient receiving Calcifediol Orally

\section{Recommendations}

We, therefore, agree with the findings of numerous studies that vitamin D supplementation can prevent COVID-19 incidence, symptoms, and severity, and can reduce the risk of spread of COVID-19. In contrast to vaccines and other drugs, vitamin D3 is a natural body product of proven safety. Recognition of vitamin $D$ deficiency as a public health problem and implementation of population-based interventional strategies by governing bodies is the most pressing need of the hour.

1. The Endocrine Society of India recommends 400 international units (IU) of vitamin $D$ a day for infants, 
600-1000 IU for children, 1000 IU for adolescents and pregnant women after 12 weeks gestation, and 1000-2000 IU for adults vitamin D supplementation for Indian people to combat the country's high prevalence of vitamin D deficiency. ${ }^{15}$ However, we believe that this level of supplementation will only suffice for the prevention of rickets, and its adult equivalent, osteomalacia; in order to optimise defensive immunity, a much higher dose is necessary. ${ }^{16}$

2. For adults: $\mathbf{3 0 0 0} \mathrm{IU}$ each day for a $60 \mathrm{~kg}$ adult, and 6000 IU each day for a $120 \mathrm{~kg}$ obese adult. Alternatively, approximately 7 times as much can safely be taken once a week.

3. For pregnant and lactating women: There is strong evidence that pre-eclampsia is linked to vitamin D deficiency. ${ }^{17}$ Vitamin D supplementation during pregnancy improves maternal and infant 25(OH)D concentrations and may play a role in maternal insulin resistance and foetal growth. ${ }^{18}$ Infant growth can be improved by vitamin D supplementation in pregnancy which also reduces the risk of SGA, without increasing the risk of congenital abnormality or foetal/ neonatal mortality. It is estimated that a dose of $2000 \mathrm{IU} / \mathrm{d}$ may help in mitigating the risk of foetal/ neonatal mortality. ${ }^{19}$ Therefore, vitamin $D$ deficiency must be actively avoided throughout pregnancy, necessitating supplementation of 2,000 to 4,000 units of vitamin D daily which has been shown to be completely safe. Achieving optimal blood levels helps to minimise complications of pregnancy and also to mount an effective primary immune response in the event of COVID-19 disease. ${ }^{20}$ This is in contrast to the WHO recommendation of a mere 200 units daily which is clearly far too low, and this supplementation should also be continued during breastfeeding as it further helps to maintain adequate levels in the breastfed infant.

4. For newborn and young children: Although the main consideration in this age group is to prevent rickets, maintaining levels sufficient for activation of immune system is of paramount importance. Vitamin D is excreted in mother's milk, provided maternal intake is adequate. To be safe, the newborn should thereafter be given 400 units daily, scaling up to 1000 units daily at age one year and 2000 units from age 5 years onwards. These doses can conveniently be given all at once, once a week, or even once monthly. 100 units of vitamin D per kilogram body weight per day being a good guide.

It must be recognised that although vitamin $D$ in its natural state is excellent in the prevention of the damaging effects of COVID-19, people who are seriously ill requiring admission to hospital must be treated with vitamin D in its activated form of calcifediol, 25(OH)D. The reason is that the activation of vitamin $D$ in the liver is a slow process. It might take two weeks before the deficiency is corrected to achieve an ideal blood level of 25(OH)D. This is too slow to be of help to the critically ill, and this has been demonstrated in Brazil. ${ }^{22}$ However, if calcifediol itself is given, it reaches an ideal level within two hours, and this is the reason for its dramatic benefit. ${ }^{23}$

Table I.Recommendations of Vitamin D for Various Groups of Population

\begin{tabular}{|c|c|}
\hline Age Group & Recommendations \\
\hline For newborn and young children & $\begin{array}{c}400 \mathrm{IU} / \text { day scalable } \\
\text { to } 1000 \mathrm{IU}\end{array}$ \\
\hline $\begin{array}{c}\text { For children of age more than } 5 \\
\text { years }\end{array}$ & 1000 - 3000 IU/day \\
\hline $\begin{array}{c}\text { For pregnant and lactating } \\
\text { women }\end{array}$ & $\begin{array}{c}3000 \mathrm{IU} / \text { day for an } \\
\text { individual of } 60 \mathrm{~kg} \\
6000 \text { IU/day for an } \\
\text { individual of } 120 \mathrm{~kg}\end{array}$ \\
\hline $\begin{array}{c}\text { For COVID-19 positive patient } \\
2000 \text { - 4000 IU/day }\end{array}$ & $\begin{array}{c}1 \text { amp of } 600000 \mathrm{IU} \\
\text { IM stat }\end{array}$ \\
\hline $\begin{array}{c}\text { Adjunctive Pulse D therapy can } \\
\text { be added safely to the existing } \\
\text { treatment protocols of COVID-19 } \\
\text { for improved outcomes }\end{array}$ & $\begin{array}{c}\text { Therapeutic } \\
\text { improvement in } \\
\text { vitamin D to } 80- \\
100 \text { ng/ml }\end{array}$ \\
\hline
\end{tabular}

The presence of a global COVID-19 pandemic affecting the immune system warrants a prompt response. Large scale supplementation of vitamin $D$ is a feasible and effective solution as it is cheap, readily available, has an easy mode of administration and can be made widely available through out-patient clinics, PHC etc. Therefore, the authors recommended that inclusion of vitamin $D$ in national and state-level treatment guidelines would be a highly beneficial and cost-effective strategy.

\section{Conflict of Interest: None}

\section{References}

1. Dixit V, Garg B, Mehta N, Pegrum J, Dhanwal D. COVID-19 infection, inception and immunity: Observations and recommendations in the light of vitamin D? J Infect Public Health. 2021 Apr 1;14(4):444-5. [PubMed] [Google Scholar]

2. Bilezikian JP, Bikle D, Hewison M, Lazaretti-Castro M, Formenti AM, Gupta A, Madhavan MV, Nair N, Babalyan V, Hutchings N, Napoli N, Accili D, Binkley N, Landry DW, Giustina A. Mechanisms in endocrinology: vitamin D and COVID-19. Eur J Endocrinol. 2020 Nov 1;183(5):R133-47. [PubMed] [Google Scholar]

3. Vyas N, Kurian SJ, Bagchi D, Manu MK, Saravu K, 
Unnikrishnan MK, Mukhopadhyay C, Rao M, Miraj SS. Vitamin D in prevention and treatment of COVID-19: current perspective and future prospects. J Am Coll Nutr. 2020 Sep 1:1-14. [PubMed] [Google Scholar]

4. Holick MF. Sunlight and vitamin D for bone health and prevention of autoimmune diseases, cancers, and cardiovascular disease. Am J Clin Nutr. 2004 Dec;80(6):1678S-88S. [PubMed] [Google Scholar]

5. Holick MF, Binkley NC, Bischoff-Ferrari HA, Gordon CM, Hanley DA, Heaney RP, Murad MH, Weaver $\mathrm{CM}$; Endocrine Society. Evaluation, treatment, and prevention of vitamin D deficiency: an Endocrine Society clinical practice guideline. J Clin Endocrinol Metab. 2011 Jul;96(7):1911-30. [PubMed] [Google Scholar]

6. Ministry of Health and Family Welfare [Internet]. Home; [cited 2021 Jun 9]. Available from: https://www.mohfw. gov.in/index.html

7. The Hindu BusinessLine [Internet]. At current rate, India will take 2.5 years to vaccinate $75 \%$ of its population; [cited 2021 Jun 9]. Available from: https://www. thehindubusinessline.com/news/at-current-rate-indiawill-take-25-years-to-vaccinate-75-of-its-population/ article34552171.ece

8. Aparna P, Muthatal S, Nongkynrih B, Gupta SK. Vitamin D deficiency in India. J Family Med Prim Care. 2018 Mar-Apr;7(2):324-30. [PubMed] [Google Scholar]

9. Ilie PC, Stefanescu S, Smith L. The role of vitamin D in the prevention of coronavirus disease 2019 infection and mortality. Aging Clin Exp Res. 2020 Jul;32(7):11958. [PubMed] [Google Scholar]

10. Kaufman HW, Niles JK, Kroll MH, Bi C, Holick MF. SARS-CoV-2 positivity rates associated with circulating 25-hydroxyvitamin D levels. PLoS One. 2020 Sep 17;15(9):e0239252. [PubMed] [Google Scholar]

11. Padhi S, Suvankar S, Panda VK, Pati A, Panda AK. Lower levels of vitamin D are associated with SARS-CoV-2 infection and mortality in the Indian population: An observational study. Int Immunopharmacol. 2020 Nov;88:107001 [PubMed] [Google Scholar]

12. Nogués $X$, Ovejero $D$, Pineda-Moncusi $M$, Bouillon $R$, Arenas D, Pascual J, Ribes A, Guerri-Fernandez R, VillarGarcia J, Rial A, Gimenez-Argente C, Cos ML, RodriguezMorera J, Campodarve I, Quesada-Gomez JM, GarciaGiralt N. Calcifediol treatment and COVID-19-related outcomes. J Clin Endocrinol Metab. 2021;dgab405. [PubMed] [Google Scholar]

13. Jayawardena R, Jeyakumar DT, Francis TV, Misra A. Impact of the vitamin D deficiency on COVID-19 infection and mortality in Asian countries. Diabetes Metab Syndr. 2021 May-Jun;15(3):757-64. [PubMed] [Google Scholar]

14. Rastogi A, Bhansali A, Khare N, Suri V, Yaddanapudi N,
Sachdeva N, Puri GD, Malhotra P. Short term, high-dose vitamin D supplementation for COVID-19 disease: a randomised, placebo-controlled, study (SHADE study). Postgrad Med J. 2020 Nov 12. [PubMed] [Google Scholar]

15. Mudur G. Indian endocrinologists set guidance to combat vitamin D deficiency. BMJ. 2015 Nov 9;351:h5997. [PubMed] [Google Scholar]

16. Grimes DS. Covid-19 \& Vitamin D - summaries of evidence [Internet]; 2020 Oct 9. Available from: www. drdavidgrimes.com/2020/10/covid-19-and-vitamin-dsummary-of.html

17. Purswani JM, Gala P, Dwarkanath P, Larkin HM, Kurpad A, Mehta S. The role of vitamin D in pre-eclampsia: a systematic review. BMC Pregnancy Childbirth. 2017 Jul;17(1):231. [PubMed] [Google Scholar]

18. Gallo S, McDermid JM, Al-Nimr RI, Hakeem R, Moreschi JM, Pari-Keener M, Stahnke B, Papoutsakis C, Handu D, Cheng FW. Vitamin D Supplementation during Pregnancy: An Evidence Analysis Center Systematic Review and Meta-Analysis. J Acad Nutr Diet. 2020 May;120(5):898-924.e4. [PubMed] [Google Scholar]

19. Bi WG, Nuyt AM, Weiler H, Leduc L, Santamaria C, Wei SQ. Association Between Vitamin D Supplementation During Pregnancy and Offspring Growth, Morbidity, and Mortality: A Systematic Review and Meta-analysis. JAMA Pediatr. 2018 Jul 1;172(7):635-45. [PubMed] [Google Scholar]

20. Hollis BW, Johnson D, Hulsey TC, Ebeling M, Wagner CL. Vitamin D supplementation during pregnancy: double-blind, randomized clinical trial of safety and effectiveness. J Bone Miner Res. 2011 Oct;26(10):234157. [PubMed] [Google Scholar]

21. Dawodu A, Tsang RC. Maternal vitamin D status: effect on milk vitamin D content and vitamin D status of breastfeeding infants. Adv Nutr. 2012 May;3(3):353-61. [PubMed] [Google Scholar]

22. Murai IH, Fernandes AL, Sales LP, Pinto AJ, Goessler KF, Duran CS, Silva CBR, Franco AS, Macedo MB, Dalmolin $\mathrm{HH}$, Baggio J, Balbi GG, Reis BZ, Antonangelo L, Caparbo VF, Gualano B, Pereira RM. Effect of a Single High Dose of Vitamin D3 on hospital length of stay in patients with moderate to severe COVID-19: a randomised clinical trial. JAMA. 2021;325(11):1053-60. [PubMed] [Google Scholar]

23. Lakkireddy M, Gadiga SG, Malathi RD, Karra ML, Raju IS, Ragini, Chinapaka S, Baba KS, Kandakatla M. Impact of daily high dose oral vitamin D therapy on the inflammatory markers in patients with COVID 19 disease. Sci Rep. 2021 May 20;11(1):10641. [PubMed] [Google Scholar] 